\title{
WHAT IS ‘ACADEMIC LEGAL WRITING’?
}

By Danie Brand*

\section{Introduction}

In the editors' note to the inaugural edition of the Pretoria Student Law Revie (PSLR) the editors wrote that the purpose of the PSLR is to serve as a platform for students to engage in 'academic legal writing'. To students interested in publishing in the PSLR, or any other law journal for that matter this might raise the questions: 'What is academic legal writing?'; 'Are there other forms of legal writing?'; and 'If so, how are they different from academic legal writing?'

These are important questions. They certainly do not only arise for potential student authors for the PSLR, but all law students who at some stage of their studies have to write 'academic' essays or dissertations, somehow different from 'practical' exam and test answers or pleadings for moot courts, or pretend-contracts. They also confront legal academics on a daily basis when they think about the nature and purpose of their work. I attempt here some answers to them.

\section{Different kinds of legal writing}

As any kind of 'doing' law - whether legal practice in whatever form; teaching law; or legal academia - centrally involves writing and the research that undergirds it, let me start by trying to identify different kinds of legal writing. I would say that there are four.

First, there is legal writing in practice. Whether one practices as an advocate; an attorney; a judicial officer or a legal advisor or whatever else, a central part of one's work will be writing and research. Advocates (and sometimes attorneys) write pleadings, affidavits, opinions and memoranda; attorneys draft notices of different kinds, contracts and memoranda; judicial officers write judgments; legal advisors give their advice on the basis of research and in writing.

Second, there is legal writing for practice. Practitioners or sometimes legal academics write what are generally called reference

* Associate Professor in Public Law, University of Pretoria. 
works for use in practice - authoritative statements of the positive law on a topic at a given time that practitioners can use in their day to day work to determine the current legal position on a point or to remind them of a process or form to follow. Examples of such reference works that emanate from my Faculty at UP are Van Loggerenberg's well-known Jones \& Buckle: The civil practice of the magistrates' courts in South Africa ${ }^{1}$ and Harms' Amler's precedents of pleadings. ${ }^{2}$

Third there is legal writing for education. All law students are during their studies exposed to textbooks on different topics - books written for use by law teachers in their teaching and law students in their studying. Examples would be Van der Walt and Pienaar's Property law ${ }^{3}$ and Theophilopoulos, Van Heerden and Boraine's Fundamental principles of civil procedure. ${ }^{4}$

Fourth and finally there is academic, or as it is also called, scholarly legal writing - the writing that legal academics, sometimes practitioners and often law students engage in for postgraduate research (doctoral theses, LLM dissertations) or for academic publication in journals or as books. Examples of scholarly/academic journal articles in South Africa would be Klare's 'Legal culture and transformative constitutionalism' $; 5$ Cockrell's 'Substance and form in the South African law of contract'; 6 and Davis' 'Adjudicating the socio-economic rights in the South African constitution. Towards "deference lite"'? 9 Examples of scholarly books in turn are Malan's Politocracy ${ }^{8}$ and Van der Walt's Property in the margins. ${ }^{9}$

\section{The distinction}

How does this last category of legal writing - academic/scholarly writing - differ from writing in and for practice and educational legal writing? Stated differently, how should prospective authors for the PSLR determine whether they are indeed engaging in the kind of 'academic legal writing' that the editors of the journal expect of them?

There are two bases upon which to my mind one can distinguish academic/scholarly from other kinds of legal writing - the nature of

\footnotetext{
DE van Loggerenberg (ed) Jones \& Buckle: The Civil Practice of the Magistrates' Courts in South Africa (10th ed 2012).

LT Harms Amler's precedents of pleadings (7th ed 2009).

AJ van der Walt \& GJ Pienaar Property law (6th ed 2009).

C Theophilopoulos, CM van Heerden \& A Boraine Fundamental principles of civil procedure ( $2 \mathrm{~d}$ ed 2012 ).

(1998) 14 South African Journal on Human Rights 146.

(1992) 109 South African Law Journal 40.

(2006) 22 South African Journal on Human Rights 301.

K Malan Politocracy (2012).

AJ van der Walt Property in the margins (2009).
} 
the writing and the research on which it is based and the basic purpose of the writing.

\subsection{A distinction in nature}

Writing in practice, writing for practice and educational legal writing all share a similar nature - they are all basically descriptive and analytical in nature. When an advocate prepares for and drafts the pleadings for a trial, she seeks in the first place to describe the existing law on point accurately and then to analyse that law to assess how it applies to the facts of her case. Retired judge Louis Harms, when he updates his Amler's precedents and pleadings, equally in the first place attempts to describe the existing law accurately and in an up-to-date fashion and then to analyse that law so that he can present it to practitioners in a useful fashion. Andre van der Walt and Gerrit Pienaar, when working on a new edition of their Property law also attempt to describe and analyse the existing law of property in such a fashion that it is clear to students and lecturers can use it to explain and teach.

Although good academic writing will always contain a healthy dose of description and analysis its basic nature is not in the first place descriptive and analytical. Instead, the description and analysis that one finds in academic writing stands in service to its real nature. Academic writing is different from other forms of legal writing in that it is primarily conceptual or theoretical in nature - when writing academically one seeks to engage on a conceptual/theoretical level with the law (that one inevitably also has to describe and analyse, of course) rather than that one seeks to describe and analyse alone. What does this mean? Lourens du Plessis, a prominent South African purveyor of academic/scholarly legal writing once described a theoretical or conceptual approach as one that does not have an immediate, descriptive relationship with its subject matter, but instead takes one step back from the immediate and attempts to generate general explanations or justifications for its subject matter; or to critique existing such general explanations or justifications; or to identify the principles upon which a particular area of law is based or to critique existing such principles. ${ }^{10}$ Academic/scholarly legal writing shows this basic approach to its subject matter. When Karl Klare wrote his 'Legal culture and transformative constitutionalism' in 1998, he certainly described and analysed in the first place the text of the 1996 South African Constitution and a series of decisions of the Constitutional Court. But he then went further: he sought to develop a general explanation for the constitution and constitutional adjudication, an over-arching approach of 'transformative 
constitutionalism'. When André van der Walt more recently wrote his Property in the margins he certainly started by providing an expert description and analyses of his subject matter - property law - but he then went further and developed a general theory of property law that conceptualises it from the perspective of those at the margins of society rather than, as is usually the case, from the perspective of the propertied, those at the centre of society.

\subsection{A distinction in purpose}

Writing in and for practice and educational legal writing all have a distinct utilitarian and practical purpose. An advocate writing a legal opinion on brief from an attorney does research and writes to address and resolve a practical legal problem raised by a case or dispute in real life. Danie van Loggerenberg when working on a new service of Jones and Buckle aims to present the current position in procedure in the magistrates' courts in such a way that practitioners can easily access and use that information in their daily practical work. Andre Boraine when he and his colleagues work on a new edition of the procedural law textbook will try to present it in such a fashion that the information can be understood and internalised by law students so that they have the basic knowledge and skill about civil procedure that they require to enter some form of legal practice - their purpose is educational.

Academic/scholarly legal writing in turn has a different, much less utilitarian and perhaps more amorphous purpose. Here is where others might disagree with me, but to mind legal writing is only scholarly/academic if it has as its primary purpose the development of legal thought and legal theory - in my own context, if it has as its primary purpose the development of South African legal thought and theory. When Koos Malan wrote his book 'Politocracy' he sought to develop an overarching theory of the law relating to living together in a multicultural society in order to contribute to the development of the law in that respect - indeed, he makes proposals for new ways of regulating public decision making and lawmaking in this context. When Dennis Davis wrote his 'Adjudicating the socio-economic rights in the South African constitution. Towards "deference lite"' he described and analysed the socio-economic rights jurisprudence of the South African Constitutional Court not simply to provide a description of that area of law, but so that he could identify the underlying principles and approach informing that jurisprudence, critique it and propose a different overarching theoretical approach. The purpose is in other words not in the first place as with other forms of legal writing practical, to contribute to the practice of law, but to contribute to the broader development of law, legal thought and theory. 


\section{Conclusion}

The distinction that I describe above should of course not be applied too rigidly. Two points to qualify it. The first is that, whatever the difference between academic and other kinds of legal writing, it is not one of quality but one of kind. It might be that some practitioners in principle sniff at the work that academics do and that some academics dismiss the writing and research of practitioners out of hand. If that happens, that is simply reciprocal snobbery or professional jealousy. The truth is that there is excellent research and writing in both practice and academia, just as there is in both contexts some pretty bad or average writing and research - but good or bad, research and writing of different kinds. Indeed, as any good practitioner or academic will profess, pure academic writing is often very useful for practitioners, just as pure practical writing can be very instructive for academics (although whether this is the case is no measure of the quality of either!).

The second is that whatever conceptual distinction one can make between academic and other kinds of legal research and writing cannot be absolute - as no distinction or categorisation can be watertight. Whichever basis one chooses for the distinction, there is bound to be a large measure of overlap between the different genres of legal writing $-\mathrm{a}$ book might for example be both a practitioners' reference work and a student textbook, or, more to the point, a practitioners' reference work might show some characteristics of a scholarly/academic work. The most one can say is that an academic work is one that primarily shows certain characteristics, rather than that those characteristics are an add-on to some other basic nature. To extend this point, practitioners can and do certainly sometimes engage in scholarly writing, just as academics often engage in writing in and for practice: of the three examples of scholarly articles I mentioned above, one (Cockrell's) was written by an advocate at the Johannesburg Bar and another (Davis') by a sitting judge. And perhaps this is the point - if you are to work in law one day in whatever capacity you will inevitably write and write a lot. It will be important to know for whom and for what purpose you write - what kind of legal writing you engage in - so that you ensure that your writing fits its particular context. But in the end the most important thing would remain to do whatever kind of legal writing you end up in carefully and well. 